\title{
Introduction: Getting to It, or A Special Way of Beginning
}

\author{
by Roger D. Abrahams
}

Counting-out is one important way of getting into play, used by children of about ages six to eleven. It provides a frame and a break between the stream of ordinary activity and the specially licensed behavior we call playing. It is a formulaic and ritualized way of focusing energies for those who wish to play games more complex than "Tag," but less coordinated in focus than team sports. It is the special way of beginning games and contests which comes after the simple touching of "Tag" and before the more elaborate ways of choosing-up sides. In fact, the most common term in American English is probably choosing-up rather than counting-out. Beginnings are always difficult when the experience is prospectively a special and licensed one; counting-out provides an activity in which the beginning is conventionally brought into play, therefore apparently not under the control of any one of the players. Counting-out rhymes are the formularized and conventional performative acts by which it is chosen out and games are begun.

It is essential that these rhymes be recognized as performatives (this derives from the speech act theory of J. L. Austin), as speech acts which actually do what they say they are doing at the point of utterance. This places them in the same category as "I dub thee knight" and "I pronounce you man and wife," but only as long as the play world is maintained. They have the power to transform individuals from one role to another, but unlike the other performatives they exist only within the ritualistic context of game and have no carryover into other domains of life. Being it is far from a permanent condition.

The formulae of counting-out are relieved of the need 
to communicate anything but the message "Everything that follows is play." Thus, the hocus-pocus language of the rhymes is central to their licensing function. Among other operations, it marks the shift of worlds by switching the pronoun system of reference from the personal to the impersonal; there are no meaningful I's or you's in any "Eeny meenies"; there are only it's. The distinction is not trivial.

With these rhymes we are involved with a number of fictions, of course. Playing rests on the presupposition that there may be significant patterns of movement and motive which are not under the obligation to produce anything; and if something happens to happen, the consequences of the product are not to be personally assigned (at least in the ideal). We know, however, from our long experience at playing that this relief from consequences is a very limited license; it applies only when the rules are closely followed and the personal integrity of others maintained. We do not commonly lose sight of our other selves while engaged in play, for to do so is to risk the consequences of having the play spill back over the frame into the "real" world. Under such conditions we may be called to account for our destructive or over-serious behavior-usually by being called a bad sport. But we also know that play will not be meaningful if we are not fearful, at all times, of the motives of the real world invading play. As Gregory Bateson notices, the message "This is play" must be accompanied by another voice asking "Is this really play?" for the special balance of enjoyment and anxiety to be brought to bear in playing. ${ }^{1}$ To put it in its simplest terms, when someone becomes it we must simultaneously know that its touch will not harm us in any way and yet dread this touch in the deepest way. (It is called the devil in some game-traditions). Furthermore, just as we are both delighted by and fearful of the proximity of it, we also must want both to be it and yet to become not-it as quickly as possible. The it-principle is one of unalloyed power; branding someone in this way makes the player a pariah, but a very attractive one who can positively affect the lives of everyone around.

Perhaps the only role more powerful than it is that of the one who gets to do the choosing-up, the count- 
ing-out, as Kenneth S. Goldstein has demonstrated in the only study that we have been able to find on the strategies of counting-out. ${ }^{2}$ There are numerous devices which one employs to manifest this power by modifying the formulae. To be sure, the existence of the rhyme seems to establish that an impersonal and traditional means is being brought into play to establish who is going to be imbued with the power of it; but there are all sorts of ways in which the counter may expand or contract the formula to make sure that the right person will be chosen. To the "Eeny meeny" routine may be added, for instance, "My mother told me to choose this one," and if this is not sufficient, "And out goes you," and if more is needed, "You dirty old dishrag, you." Enough is enough in everything but counting-out and dealing with the Internal Revenue Service and the mortician.

Furthermore, the condition of being it is characteristic of games which need some help in beginning but which seem to have no equivalent formula for ending. These are not really games in which winning or losing is important. The only appropriate ending to the condition begun with "One potato, two potato" seems to be "Olly olly in free," a serendipitous decision not to play any more-or at least not to play that game any more.

What seems to be involved when counting-out rhymes are employed is the making complex of the simple activity of getting into play. The rhymes establish a distance between the real and the play worlds more profound than that implied by simply saying "Tag, you're it." Moreover, the games which are framed in this way are ones, like "Kick the Can" and "Hide and Seek," in which negotiations of status and classification have become intermingled; thus the initial choosing of it established the vocabulary and the rhetoric by which the role of the distribution of power can be negotiated.

This process is not that far removed from the "Tag, you're it" approach in terms of how power to choose is seized. Danielle Roemer has noted a number of these scenes of role manipulation when children come out to play. ${ }^{3}$ Appropriately, she has called the first stage of the negotiation for who will lead the choosing-up, "the 
bid." The process she describes also employs, in the bidding, a choice of which rhyme will be employed, and the power to explain how the counting will be done:

JACK: Wait a minute. I got it. I got it. I got it.[bid]

Put out these [puts out his fists].

Engine, engine ...

In this case, the role of counter was simply appropriated. In the next, acquiescence was solicited and received, through a recognition that choosing up initially involves a choice of rhymes.

SAUNA: I have a good 'un.

CANI: O.K.

SAUNA: Put your hands in, 'K?

KATIA: 'K.

SAUNA: Monkey, monkey ...

If one takes on the role of counter, it must be carried out with fluency or the bidding will begin again, with someone else often winning. Similarly, the competitive bidding may result in more than one person beginning the counting-out, in which case the loudest (or strongest) usually triumphs.

That counting-out is a game to begin a game is, then, apparent. Indeed, there are certain elaborate rhymes included in this volume which are commonly employed apart from any other game, especially "Intery, mintery, cutery, corn" (no. 287).

There have been some important collections of counting-out rhymes in English: Bolton and Withers are the two that come to mind immediately. ${ }^{4}$ Little attempt has been made in these collections to come to grips with either the contrived strangeness of these rhymes or how they are employed in the increasingly complex process of socialization among children. Just why this should be is difficult to ascertain, for they are certainly as rich, as abundant, and as available as, say, riddles. Among others, Martha Wolfenstein and Brian Sutton-Smith have found in such joking enigmas some key insights into childhood developmental processes, the former with regard to testing out motives of power and sexuality, the latter with regard to discernment of staged levels of verbal and concept control. ${ }^{5}$ 
These rhymes, then, are a sonorous accompaniment to negotiations in an ego-centered classification and reclassification contest. The play world encourages precisely this playing around with received social and cultural orders, much as riddling does in the confronting of the child's concepts of the order of things. What Sutton-Smith points out with regard to riddles at ages six to eighteen describes important features of other kinds of play, including games: "at about the age when riddles peak, children show their initial competence in problems of verbal classification, reclassification and multiple classification." 6 The major point of counting-out is to establish the order of play and players in many dimensions by repetition of numbers and number-like classifiers. Counting-out does just what it announces itself as doing; it makes ciphers of players, allowing them to enter into the temporarily declassified and meritocratic world of play, a world in which you are what you become through your ability to control your body while mastering the rules of the game-and the rules for changing the rules.

But the game play begun by this elaborate framing device is more than just a classificational scheme in preparation for a possible reclassification through reordering. We are involved with learning to understand "multiple classification" here as well, that complex state of mind in which someone (or something) can stand for something and its very opposite, and at the same time! In its riddling equivalents, the message is boldly presented:

What has ears and cannot hear?

Corn.

What is it the more you take from it the larger it grows?

A ditch.

What goes up the chimney down but not down the chimney up?

An umbrella.

These are only verbal contradictions, however, and in games the contradictory states are considerably more existential. In the games begun with counting-out, the ones being chosen are in a perilously ambiguous state, for they are endowed with the dreadful yet desirable 
power of being it. It is, in such cases, a semantic conflation of in and out, making counting-out a process both of distinguishing who's in and who's out, and of breaking down that distinction right away through the powerful quality of touch. I don't wish to make undue claims for the practice (there are a number of other ways we learn about social complexity through experiencing such contradiction), but nowhere is the existential dilemma of power and vitality more clearly to be confronted. To put it in utilitarian terms for the moment, as Sutton-Smith points out: "Children achieve an organization of personal and social behavior in play which far exceeds their ability outside of play. Thus in the hide and seek model of seven years, children achieve a role reversibility which they cannot achieve in their other social behavior until about eleven years." 7 Certainly one factor in developing this ability to change roles is arrived at through the conventionalization of both the roles and the impersonalized way of choosing them. But we might also explore the possibility that the world in which such role transformation can be brought off occurs because of the protective covering provided by counting-out, a verbal routine that makes a litany of the earliest verbal orders one learns: numbers, letters, days, and colors.

In a sense, counting-out then represents a statement of verbal control beyond phonology, such as SuttonSmith demonstrates in the riddles of this age group. Following Piaget, he notes (as mentioned above) that at this age "children show their initial competence in verbal classification, reclassification and multiple classification." 8 However, in counting-out, and jumping rope, the ambiguous classificational play is accompanied by physical movement within the agonistic frame of reference. I refer to this as "beyond phonology" only because on first blush these rhymes often seem nonsensical, a simple playing around with sounds for their own sake, while sense is being made on the level of the social world within play. Though these rhymes often seem to involve gibberish, as Sanches and Kirshenblatt-Gimblett argue, when viewed in the context of both their history and the other 
rhymes used interchangeably, even the "Eeny meeny" and "Intrery mintery" routines can be seen to be models of ordering nonsensified, "put into neutral" as it were. ${ }^{9}$ Though these rhymes do not operate under any apparent need to make sense, in fact, like most nonsense, they provide a recognition and an underscoring of the earliest verbal devices of ordering. The process is one of choosing mainly by using numbers. The context insists on this. "Eeny meeny" is, after all, a functional substitute for "One potato, two potato." All of the rhymes invoke a kind of defamiliarization of lexical series, a foregrounding of the routine set by saying the series strangely. All of this contributes to the multiple statements going on in choosing-up, all of which are reducible to one- "Everything within this frame is play ... isn't it?" The linguistic inversions simply announce the onset of other kinds of play. Physical play is preceded by verbal play, both of a highly conventionalized sort, and both replete with motives of conflict and negotiation of roles. Without this beforeplay play, the thrill of the chase and the test could never be so exquisite.

A good part of the thrill of being it (or being the one who counts out) is in the awe this inspires in the other players. Play cannot be carried out effectively, in fact, without this intensity of focus. But the power is also one which causes others to test and retreat from you. To keep the power too long, moreover, is to bring on boredom; it must be effectively passed on precisely as a measure of one's competency in the game. To pass it on too quickly, on the other hand, is also to risk making the game boring. When some imbalance between getting to be it and passing it along is encountered, the group will tend to respond by graduating to a more complicated game, as occurred in the early graduation from "Tag" to "Iron Tag," "Stoop Tag," and so on. The development of contest-forms is, indeed, a process of careful gradation and growing complexity, from "Tag," to "Hide and Seek" type games, to ones involving choosing up sides, like "Capture the Flag," to team sports. With each change the rules become more complex, the roles more varied, stylized, and convention- 
bound, and the focusing energy of it-ness altered from hand to eye ("I spy Johnny") to control over a power object.

The employment of choosing-up techniques is part of the diversification in the vocabulary of power. Controlling these rhymes is a way of introducing word play into action play, of making a statement about how the simple laying on of hands is not enough to dramatize ability and control; verbal routines parallel conventional moves and plays both in the counting-out and in the game afterward.

Use of these rhymes occurs at the same age as learning to joke. The physical trick, or catch, involves a similar deployment of verbal negotiation for a temporary physical dominance available to anyone who would seize the opportunity.
A: Did you get my letter?
B: No.
A: I must have forgotten to stamp it. [A stamps on B's foot.]
A: Adam and Eve and Pinch-Me went down to the river to swim. Adam and Eve fell in. Who was left?
B: Pinch-Me.
A: Gotcha.

Being chosen it is perhaps the biggest catch of all.

\section{Notes to the Introduction}

1. Gregory Bateson, "A Theory of Play and Fantasy," in Steps to an Ecology of Mind (San Francisco: Chandler, 1972).

2. Kenneth S. Goldstein, "Strategy in Counting-Out," in The Study of Games, ed. Elliott M. Avedon and Brian Sutton-Smith (New York: John Wiley \& Sons, 1971), pp. 167-178.

3. Danielle Roemer, unpublished paper.

4. Henry Carrington Bolton, The Counting-Out Rhymes of Children (London: Elliot Stock, 1888); Carl Withers, Counting Out (New York: Oxford University Press, 1946).

5. Martha Wolfenstein, Children's Humor (Bloomington: Indiana University Press, 1978 [reprint]); Brian Sutton-Smith, “A Developmental Structural Account of Riddles," in Speech Play, ed. Barbara Kirshenblatt-Gimblett (Philadelphia: University of Pennsylvania Press, 1976), p. 113.

6. Sutton-Smith, Speech Play, p. 115. 